BNL-52597

Formal Report

\title{
FEASIBILITY STUDY OF DUPOLY TO RECYCLE DEPLETED URANIUM*
}

\author{
TTP No. CH36MW63 \\ TASK C
}

\author{
Final Report \\ FY 1997
}

J.W. Adams, P.R. Lageraaen, P.D. Kalb, and S.P. Rutenkroger

February 1998

\author{
Prepared by: \\ Environmental \& Waste Technology Center \\ Department of Advanced Technology \\ Brookhaven National Laboratory \\ Prepared for: \\ Mixed Waste Focus Area \\ Office of Science and Technology \\ U.S. Department of Energy \\ Contract No. DE-AC02-76CH00016
}

${ }^{*}$ This work was performed under the auspices of the U.S. Department of Energy. 
This page intentionally left blank. 


\begin{abstract}
DUPoly, depleted uranium(DU) powder microencapsulated in a low-density polyethylene binder, has been demonstrated as an innovative and efficient recycle product, a very durable high density material with significant commercial appeal. DUPoly was successfully prepared using uranium tetrafluoride $\left(\mathrm{UF}_{4}\right)$ "green salt" obtained from Fluor Daniel-Fernald, a U.S. Department of Energy reprocessing facility near Cincinnati, Ohio. Samples containing up to $90 \mathrm{wt} \% \mathrm{UF}_{4}$ were produced using a single screw plastics extruder, with sample densities of up to $3.97 \pm 0.08 \mathrm{~g} / \mathrm{cm}^{3}$ measured. Compressive strength of as-prepared samples (50-90 wt $\left.\% \mathrm{UF}_{4}\right)$ ranged from $1682 \pm 116 \mathrm{psi}(11.6 \pm 0.8$ $\mathrm{MPa})$ to $3145 \pm 57 \mathrm{psi}(21.7 \pm 0.4 \mathrm{MPa})$. Water immersion testing for a period of 90 days produced no visible degradation of the samples. Leach rates were low, ranging from $0.02 \%\left(2.74 \times 10^{6} \mathrm{gm} / \mathrm{gm} / \mathrm{d}\right)$ for $50 \mathrm{wt} \% \mathrm{UF}_{4}$ samples to $0.72 \%\left(7.98 \times 10^{-5} \mathrm{gm} / \mathrm{gm} / \mathrm{d}\right)$ for $90 \mathrm{wt} \%$ samples. Sample strength was not compromised by water immersion.

DUPoly samples containing uranium trioxide $\left(\mathrm{UO}_{3}\right)$, a DU reprocessing byproduct material stockpiled at the Savannah River Site, were gamma irradiated to $1 \times 10^{9} \mathrm{rad}$ with no visible deterioration. Compressive strength increased significantly, however: up to $200 \%$ for samples with $90 \mathrm{wt} \% \mathrm{UO}_{3}$. Correspondingly, percent deformation (strain) at failure was decreased for all samples. Gamma attenuation data on $\mathrm{UO}_{3}$ DUPoly samples yielded mass attenuation coefficients greater than those for lead. Neutron removal coefficients were calculated and shown to correlate well with wt\% of DU. Unlike gamma attenuation, both hydrogenous and nonhydrogenous materials interact to attenuate neutrons.
\end{abstract}


This page intentionally left blank. 


\section{TABLE OF CONTENTS}

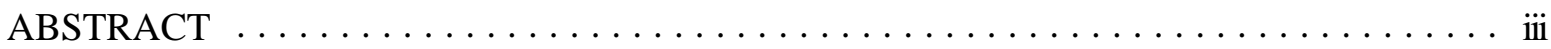

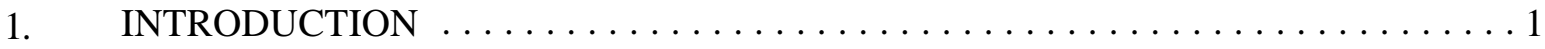

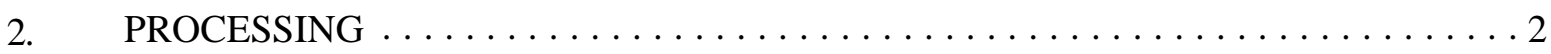

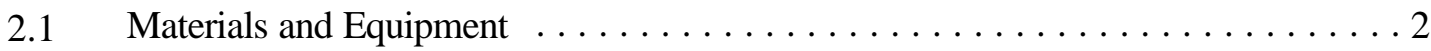

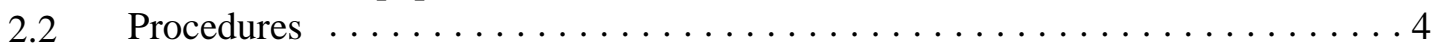

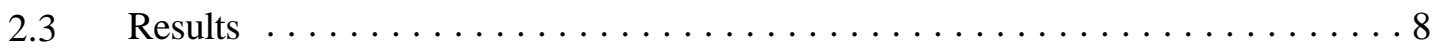

3. PRODUCT CHARACTERIZATION AND PERFORMANCE TESTING $\ldots \ldots \ldots .9$

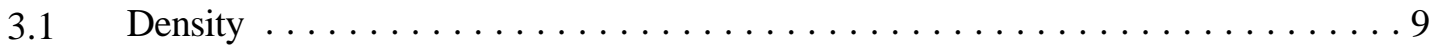

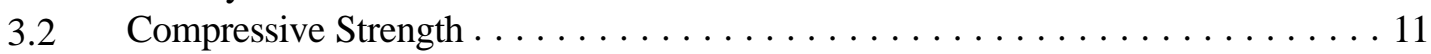

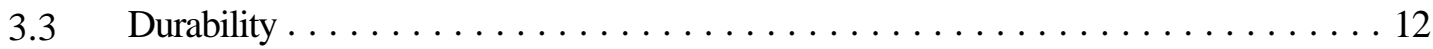

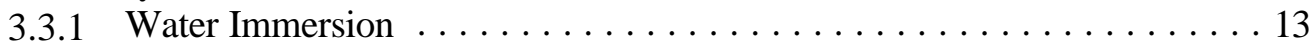

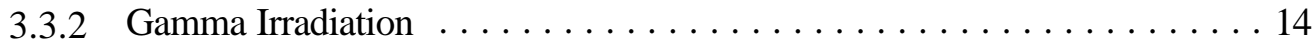

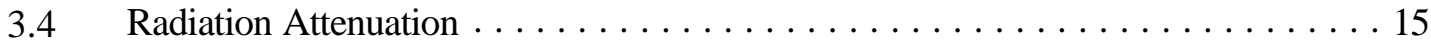

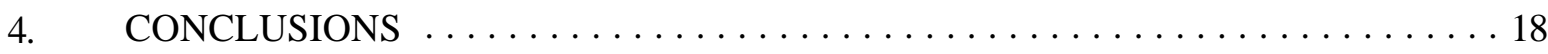

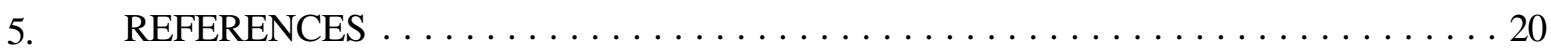




\section{LIST OF FIGURES}

Figure 1. Differential Scanning Calorimetry of As-Received $\mathrm{UF}_{4}$ Powder. $\ldots \ldots \ldots \ldots$

Figure 2. Bench-Scale Killion Plastics Extruder. $\ldots \ldots \ldots \ldots \ldots \ldots \ldots \ldots \ldots$

Figure 3. Representative $U_{4}$ DUPoly $2 x 4$ samples. $\ldots \ldots \ldots \ldots \ldots \ldots \ldots \ldots$

Figure 4. Representative $U_{4}$ DUPoly Disk, Rate, 1 1x1, and Grab Samples. . . . . . . . . 7

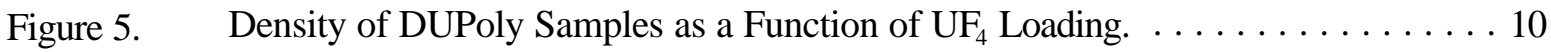

Figure 6. Compressive Strength of DUPoly Samples as a Function of $\mathrm{UF}_{4}$ Loading. . . . . . 12

Figure 7. Gamma Attenuation of "Batch Process" $U_{3}$ DUPoly Samples. . . . . . . . 16

Figure 8. Gamma Attenuation of "Continuous Process" $\mathrm{UO}_{3}$ DUPoly Samples. . . . . . . 17

Figure 9. Neutron Attenuation of "Batch Process" $\mathrm{UO}_{3}$ DUPoly Samples. . . . . . . 17

Figure 10. Neutron Attenuation of "Continuous Process" $\mathrm{UO}_{3}$ DUPoly Samples. . . . . . 18 


\section{LIST OF TABLES}

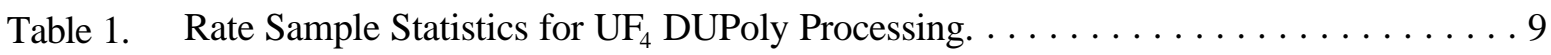

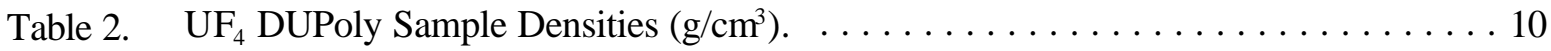

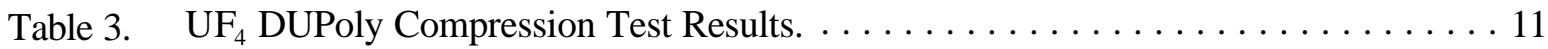

Table 4. $\quad \mathrm{UF}_{4}$ DUPoly Immersion Test Results. . $\ldots \ldots \ldots \ldots \ldots \ldots \ldots \ldots \ldots \ldots$

Table 5. $\quad \mathrm{UO}_{3}$ DUPoly Gamma Irradiation Test Results. . . . . . . . . . . . . . 14 
This page intentionally left blank. 


\section{INTRODUCTION}

Polyethylene microencapsulation is an improved treatment alternative for Department of Energy (DOE) low-level, hazardous and mixed wastes wherein particulate wastes become dispersed and stabilized within a continuous polyethylene binder. The concept has been successfully demonstrated from bench-scale processing through full-scale production using both surrogate and actual wastes.[1,2,3] Extrusion and thermokinetic mixing processes have been developed at Brookhaven National Laboratory (BNL) to treat these wastes.[4,5] These processes have been, and are being patented, and the technology is presently being transferred to the commercial sector for immediate implementation.

Following decomissioning of several of the nations nuclear processing facilities, DOE's massive depleted uranium (DU) inventory has been cited as a valuable resource for new materials development. Potential applications and markets for DU materials were thoroughly identifiedand rated.[6] Primary markets targeted were based on the high density of these materials (counterweights/ballast, flywheels, armor, and projectiles) and its radiation shielding capabilities (shielding blocks for high activity waste and high energy experimental facilities, and spent fuel dry storage/transportation casks). Although the bulk of the inventory is in the form of uranium metal or fluoride compounds, commercial processes exist to efficiently convert these relatively unstable forms into stable compounds, namely in powder form. These particulate materials were logically identified as ideal candidates for polyethylene microencapsulation. Microencapsulation is desirable in that it would stabilize these materials, mitigating their acute hazards (i.e., dispersibility, high radiotoxicity) allowing production of useful secondary products. The thermoplastic binder is re-workable, allowing easy recycling of the encapsulated product. Furthermore, if required, the DU could be readily extracted from the product.

In FY 1996, BNL completed a feasibility study on the use of DU encapsulated in polyethylene (DUPoly) for beneficial secondary use applications such as radioactive waste containers, spent fuel casks, and shielding walls.[7] $\mathrm{DU}$ in the form of uranium trioxide $\left(\mathrm{UO}_{3}\right)$ powders, obtained from Westinghouse Savannah River Site, was encapsulated in low-density polyethylene using a single-screw extrusion process. Composites ranging from 50-95 wt $\% \mathrm{UO}_{3}$ were processed, with $90 \mathrm{wt} \%$ being the practical extrudable limit. A maximum density of $4.2 \mathrm{~g} / \mathrm{cm}^{3}$ was achieved using $\mathrm{UO}_{3}$, but increased product density using uranium dioxide $\left(\mathrm{UO}_{2}\right)$ was estimated at $6.1 \mathrm{~g} / \mathrm{cm}^{3}$. Additional product density improvements up to about $7.2 \mathrm{~g} / \mathrm{cm}^{3}$ were estimated using a hybrid technique known as micro/macroencapsulation, where sintered briquettes of $\mathrm{UO}_{2}$ are encapsulated in a DUPoly matrix. Cursory performance testing included compressive strength, water immersion and leach testing. Room temperature compressive strengths were nominally >2000 psi, in keeping with measurements made with other waste materials encapsulated in polyethylene. Leach rates were relatively low $(0.07-1.1 \%)$ and increased as a function of waste loading. However, considering the insolubility of uranium trioxide, these leach data indicate the probable presence of other, more soluble uranium compounds. Ninety day water immersion tests concluded that water absorption was inconsequential except for "batch process" $\mathrm{UO}_{3}$ samples at $>85 \mathrm{wt} \%$ waste loadings. "Continuous process" $\mathrm{UO}_{3}$ samples were relatively benign to water immersion with no indication of deterioration at even the highest (90 wt\%) waste loading.

The current task included a similar feasibility study on the use of uranium tetrafluoride $\left(\mathrm{UF}_{4}\right)$ powder as an aggregate in DUPoly. Fernald, a former DOE uranium processing facility near Cincinnati, Ohio, has identified approximately 9 million pounds of DU that has not been declared as waste, approximately half of which is in the form of high purity $\mathrm{UF}_{4}$ powder. At ambient conditions, $\mathrm{UF}_{4}$ is a 
stable and very unreactive compound.[8] At elevated temperatures it converts to uranium hexafluoride in the presence of fluorine $\left(>250^{\circ} \mathrm{C}\right)$ or oxygen $\left(800^{\circ} \mathrm{C}\right)$, and will hydrolyze in the presence of water to form $\mathrm{UO}_{2}$ and hydrofluoric acid. $\mathrm{UF}_{4}$ is not hygroscopic, with a reported solubility in water of approximately $0.03 \mathrm{~g} / \mathrm{l} .[9]$ It is essentially insoluble in nitric or hydrochloric acid. Microencapsulation of DU is of potential interest to Fernald to manufacture containers for storing and shipping their own radioactive waste (in place of concrete boxes) from treatment of K-65 Silo waste. Implementation would result in significant cost savings because disposal costs for depleted uranium would be avoided, and because DUPoly shielding, which is more efficient (compared to concrete), would result in fewer boxes required for storage and transportation. Processibility of $\mathrm{UF}_{4}$ DUPoly, density and mechanical strength of the DUPoly material as a function of $\mathrm{UF}_{4}$ loading, and performance in a 90 day water immersion test were evaluated in this report.

A second goal of this task was to investigate performance of DUPoly materials under radiolytic conditions. To expedite this effort, $\mathrm{UO}_{3}$ DUPoly samples generated in the previous study were tested. The effects of gamma irradiation on material integrity were examined, as were attenuation efficiencies, viz., shielding capabilities, of both gamma and neutron collimated beams.

\section{PROCESSING}

DUPoly was prepared using a bench-scale, single-screw, non-vented plastics extruder. The maximum $\mathrm{UF}_{4}$ loading was determined. Extruder process variables (aside from DU loading) included total feed rate, screw speed, barrel temperature profile, output die temperature, and die configuration and pressure. Processibility limit is conventionally defined as the highest DU loading where the material conveys properly and consistently for all process components (material feed and extruder).

\subsection{Materials and Equipment}

Approximately 230 pounds of $\mathrm{UF}_{4}$ powder was received from Fluor Daniel-Fernald on May 19, 1997. The dark green powder, received in a single 5 gallon metal pail, was slightly compacted with a few lumps $>1 \mathrm{~cm}$. Although the material appeared dry, powder was transferred into a Pyrex trayand dried 48 hours at $160^{\circ} \mathrm{C}$ (maximum process temperature) to preclude moisture volatilization during polyethylene encapsulation processing. (Past experience has indicated gas entrainment in the product when moisture content of the bulk powder exceeds $2 \mathrm{wt} \%$.) On cooling, material was transferred to a feed hopper, which was subsequently sealed and moved into position above the extruder. Initial trial process runs at low $\mathrm{UF}_{4}$ loadings (\#50 wt\%) indicated no apparent processing problems.

Moisture content and thermal analysis was performed on the as-received powder. A $50 \mathrm{~g}$ sample oven dried at $110^{\circ} \mathrm{C}$ for $96 \mathrm{~h}$ yielded a moisture content of $0.2 \mathrm{wt} \%$. Differential scanning calorimetry, heating at $4^{\circ} \mathrm{C} / \mathrm{min}$ from ambient temperature to $300^{\circ} \mathrm{C}$, showed a single endotherm at about $134^{\circ} \mathrm{C}$, with a heat capacity of about $-0.3 \mathrm{cal} / \mathrm{g}$ (Figure 1). This endotherm was not apparent on samples which had been oven dried. Gross gamma count of a 50 gram sample yielded 53,100 dpm per gram of uranium. No quantification of the particle size distribution was performed at BNL. 


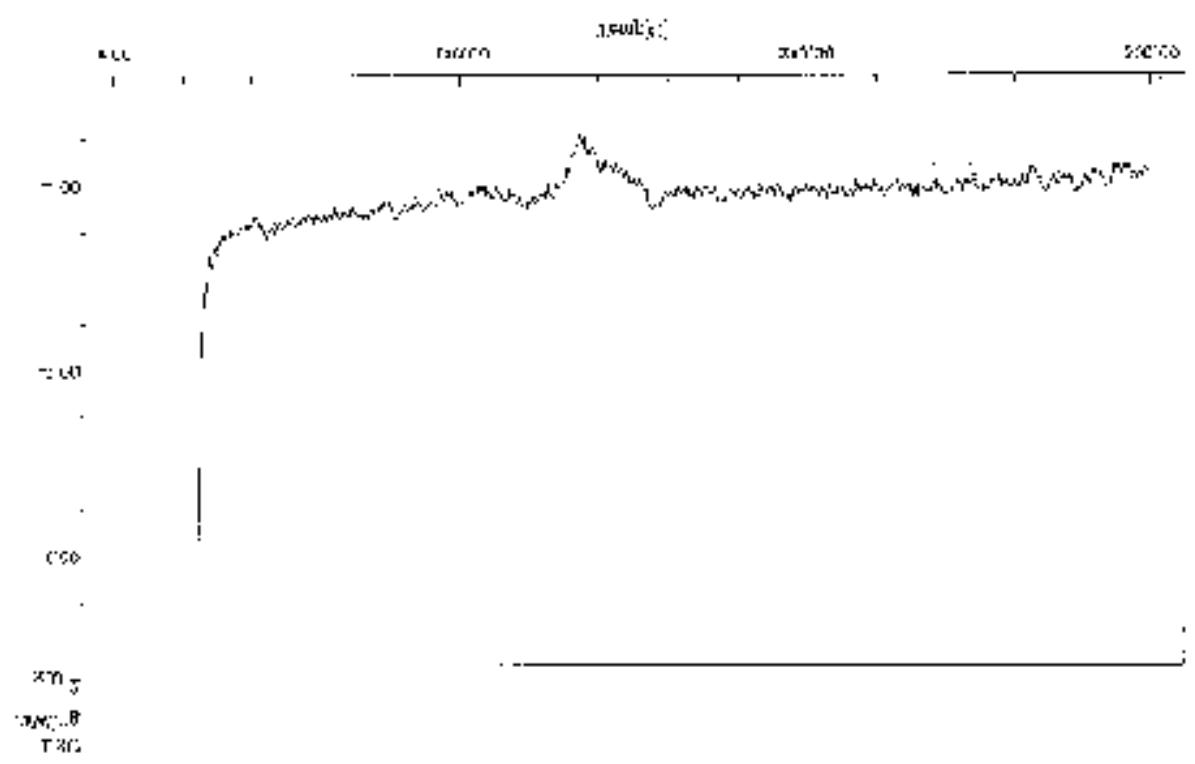

\section{Figure 1. Differential Scanning Calorimetry of As-Received $\mathrm{UF}_{4}$ Powder.}

A $32 \mathrm{~mm}$ (1.25 in.) diameter single-screw, non-vented Killion extruder, shown in Figure 2, was used for processibility testing. The extruder is equipped with a basic metering screw, three heating/cooling barrel zones and an individually heated die. DU and polyethylene are delivered separately via a $\mathrm{ft}^{3}$ AccuRate 300 Series feeders which tee into a common vertical Lucite feed tube sitting directly over the extruder feed throat. Output of these feeders is regulated independently, in real time, using a Merrick 3000 loss-in-weight feed control system. Each feeder sits atop its own scale which communicates to a master controller. Thus, individual and total feed rate, and feed mixture, can be programmed and controlled with accuracy of $<1 \%$. The binder used for all process runs was pelletized low density polyethylene produced by Chevron. 


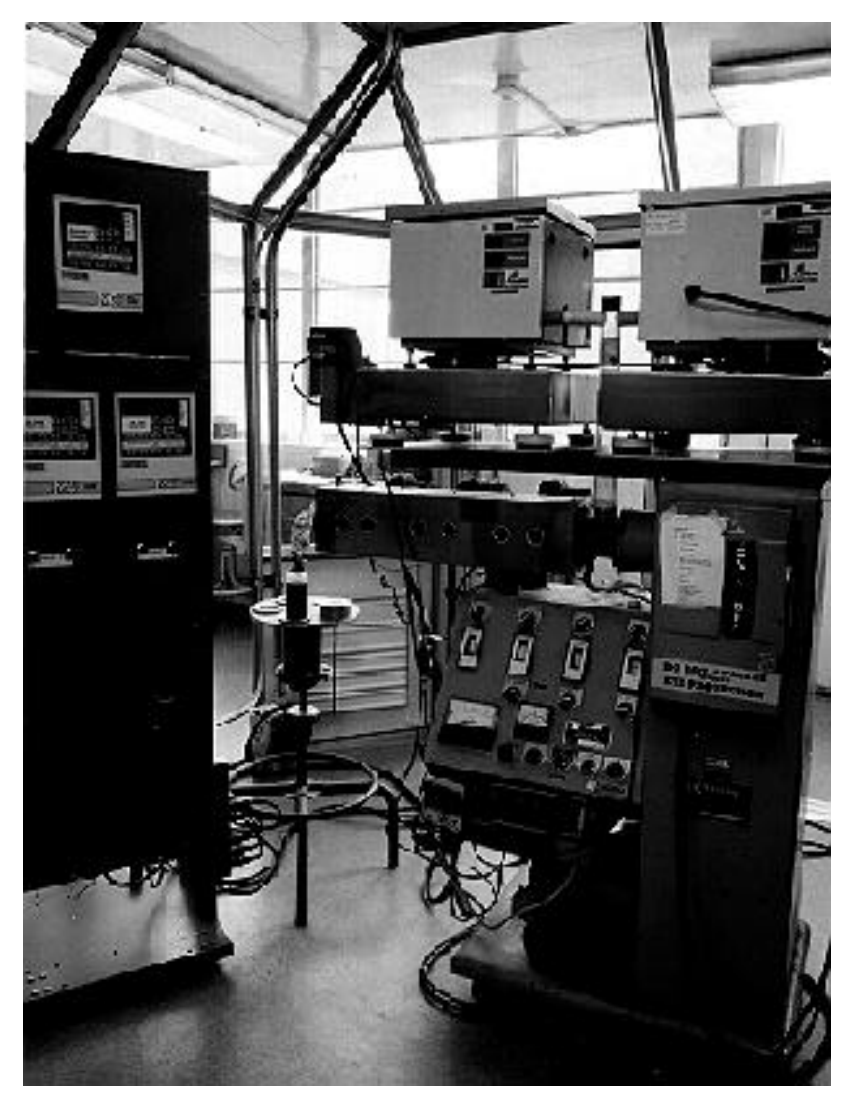

Figure 2. Bench-Scale Killion Plastics Extruder.

\section{$2.2 \quad$ Procedures}

Processibility testing included identifying key extrusion parameters such as temperature profiles (zone temperatures) and feed and process rates, as well as monitoring product appearance, consistency and throughput. Current draw, melt temperature, melt pressure and extrudate product appearance were recorded at a constant extruder screw speed to gauge whether the material was amenable to extrusion processing. 'Extrudate' refers to the stream of molten product that exits the extruder through the output die. Monitoring these processing parameters along with visual observations of feeding and output provided valuable information regarding the processibility of the DU.

A number of replicate samples (typically ten, for statistical assurance) were fabricated to quantitatively measure processing results. These samples are abbreviated as: rate, grab, $2 \times 4$, and $A L T$. Replicates of each sample were taken sequentially and periodically throughout the processibility trials at given DU loadings. Rate and grab samples are used to monitor material processibility whereas $2 \times 4$ and $A L T$ samples are used primarily to measure product performance. In addition to these processing and product samples, disk samples were also fabricated for shielding and attenuation studies. 
A descriptive narrative of each sample type is given below, followed by photographs of representative 2x4 (Figure 3) and disk, rate, 1x1, and grab samples (Figure 4).

Rate samples were taken at one minute intervals to determine extruder output (g/min) and consistency over an extrusion trial. Low variation between replicate rate samples indicates that the output is continuous and that the material can be successfully processed at that DU loading. Typically, as the loading for a given waste is increased above its processibility limit, the output becomes discontinuous with noticeable surges.

Grab samples were taken periodically over an extrusion trial as small (approximately 3-10 g) representative specimens of the extrudate. The density of each grab sample was determined by weighing and using a Quantachrome Multipycnometer to measure their volume. Monitoring the product density is useful for quality control and to ensure homogeneity of the product. Low variation between replicate grab samples indicates that the DU material is feeding well and is consistently becoming well mixed with the polyethylene as it is processed in the extruder.

$2 \times 4$ samples were fabricated as right cylindrical specimens for compressive strength and water immersion testing. The sample name refers to the nominal dimensions, 2 in. diameter by $4 \mathrm{in}$. height $(5 \mathrm{~cm} \times 10 \mathrm{~cm})$ required for compliance with ASTM D-695, "Compressive Properties of Rigid Plastics." For this project, these specimens were cast in pre-heated brass molds. Teflon plugs were inserted into the top of the mold after filling, then a slight compressive force was applied (max. $0.17 \mathrm{MPa}(25 \mathrm{psi})$ ). This technique produced smooth, uniform specimens.

ALT samples were fabricated for product leach testing in individual Teflon molds periodically throughout an extrusion trial. Samples were nominal 1 in. diameter by 1 in. high right cylinders $(2.5 \mathrm{~cm} \times 2.5 \mathrm{~cm})$, as specified by the Accelerated Leach Test (ALT), ASTM C-1308. These samples were molded under moderate compression of up to $1.72 \mathrm{MPa}(250 \mathrm{psi})$. These samples were also used to determine DUPoly densities achievable when using a compression molding technique.

Disk samples were formed in circular glass petri dishes and molded under slight compression (max. $0.17 \mathrm{MPa}(25 \mathrm{psi})$ ). Disk samples were fabricated at varying thicknesses for attenuation studies to determine the effectiveness of the product as a shielding material. 


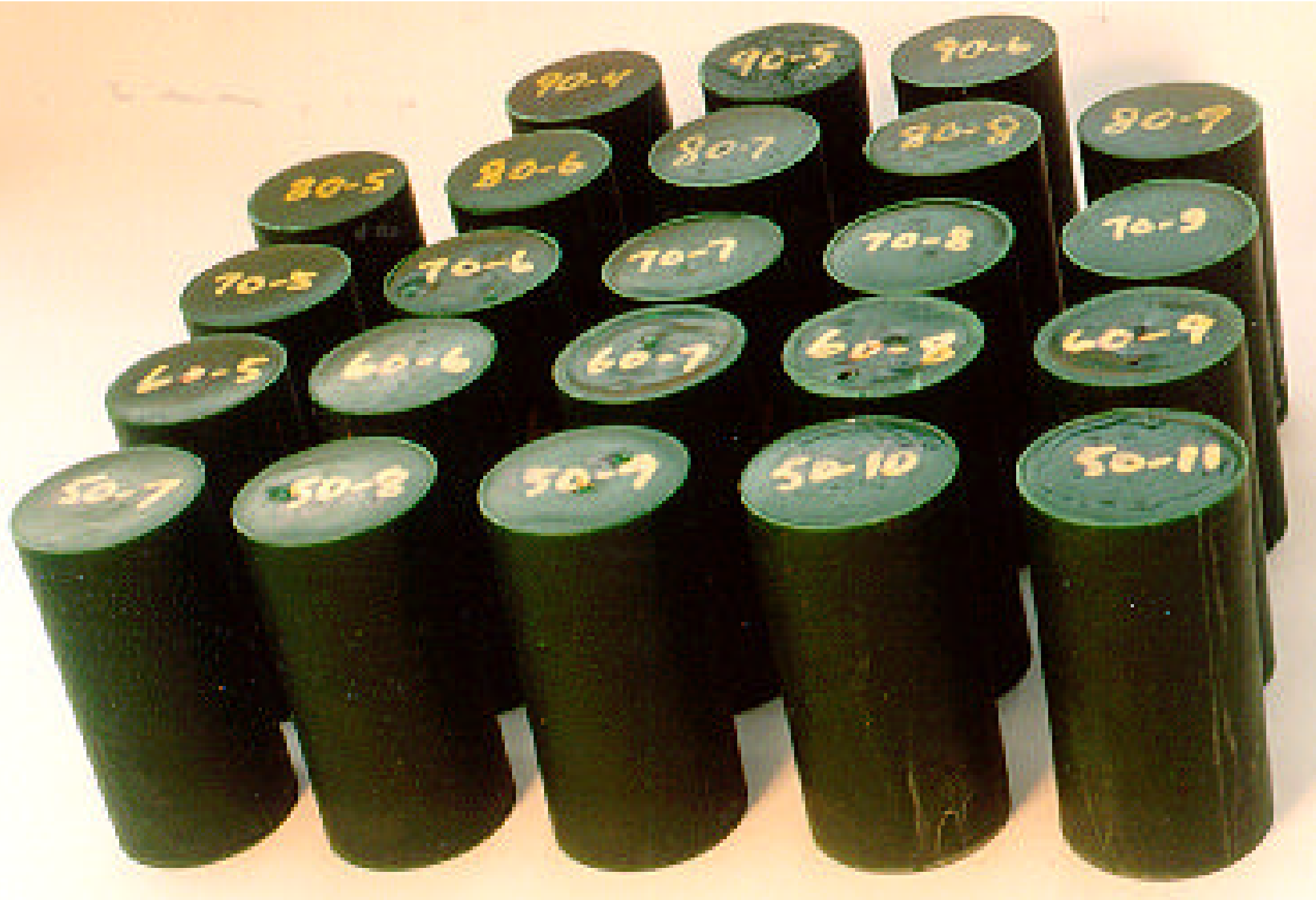

Figure 3. Representative UF DUPoly $_{4} \mathbf{2} 4$ samples. 


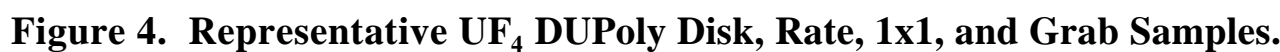

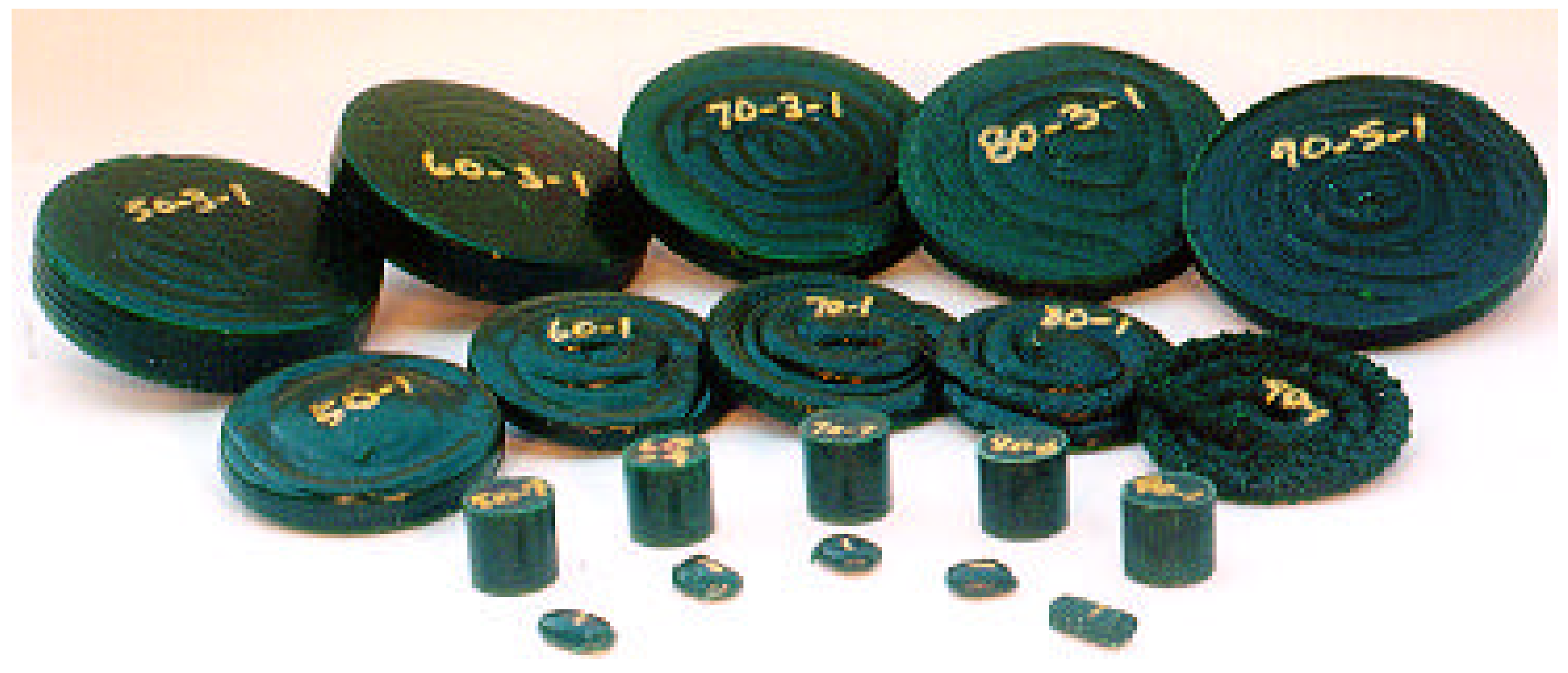




\subsection{Results}

Initial $\mathrm{UF}_{4}$ DUPoly process runs were attempted at $50 \mathrm{wt} \% \mathrm{UF}_{4}$. No extrusion processing difficulties were observed. However, loss-in-weight feeders were not operating in a steady-state condition. Following optimization of proportional-integral-derivative (PID) parameters for the $\mathrm{UF}_{4}$ feeder, and switching to a volumetric feed mode for the polyethylene feeder, erratic feed problems were rectified. Extrusion processing was thus attempted at $70 \mathrm{wt} \% \mathrm{UF}_{4}$, as per the project test plan.

At $70 \mathrm{wt} \%$ DU loading, significant processing problems were encountered. These included periodic surging, fluctuating current draw, buildup and release of gas, and erratic output. Following extensive diagnosis, including examination of waste loading, feed rates, and screw speed, processing difficulties (none of which were observed during processing of $\mathrm{UO}_{3}$ DUPoly) were finally attributed to a malfunctioning extruder temperature controller. Problems were caused by an overheating zone in the extruder, causing the polyethylene to begin to decompose and form a low viscosity wax-like product. A service representative from Killion Extruders conducted an on-site repair of the system, replacing the four temperature controllers with a matched set of PID controllers of improved design and two improperly operating band heaters. Improvements were also made to provide more precise control of the die heater.

Following repairs to the Killion extruder, $\mathrm{UF}_{4}$ DUPoly waste forms were processed at 60,70 , 80 and $90 \mathrm{wt} \% \mathrm{UF}_{4}$ loadings. Some processing difficulties continued to be observed, namely intermittent gas release through the die as evidenced by an occasional audible popping sound. This occurrence was far less frequent and severe, with no concomitant motor strain or pressure surges as observed prior to the repairs. Evolution of gas was thought to be associated with air entrained by the very fine particle size of the $\mathrm{UF}_{4}$ powder. A vented extrusion or kinetic mixing process would be expected to relieve any gas generated. At the $90 \% \mathrm{UF}_{4}$ loading, processing was deemed unsuccessful in that extrudate output was discontinuous, with output flow ceasing for periods of 15-45 seconds, then continuing for periods of 30-60 seconds. Product at $90 \mathrm{wt} \%$ did appear homogeneous, however, so that a limited number of samples were collected to characterize the material. Rate sample variability is reported in Table 1 as a function of $\mathrm{UF}_{4}$ loading. These data show relatively uniform process rates $(2 s<-10 \%)$, an indication of successful DUPoly processibility.

Table 1. Rate Sample Statistics for $\mathrm{UF}_{4}$ DUPoly Processing.

\begin{tabular}{|c|c|c|c|c|}
\hline $\begin{array}{c}\mathbf{U F}_{\mathbf{4}} \text { Loading } \\
(\mathbf{w t} \%)\end{array}$ & $\begin{array}{c}\text { Rate } \\
(\mathbf{g} / \mathbf{m i n})\end{array}$ & Std. Dev. & 2s Error & \% Error \\
\hline 50 & 128.13 & 2.43 & 1.98 & 1.54 \\
\hline 60 & 115.37 & 7.23 & 5.88 & 5.10 \\
\hline 70 & 117.77 & 6.95 & 5.65 & 4.80 \\
\hline 80 & 141.55 & 18.81 & 15.29 & 10.80 \\
\hline
\end{tabular}

3. PRODUCT CHARACTERIZATION AND PERFORMANCE TESTING 
Final products were characterized and evaluated to assess the integrity and durability of the DUPoly product for potential commercial applicability. Characterization and performance testing included density measurement, compressive strength, durability following water immersion and gamma irradiation, and radiation attenuation. The following sections detail specific procedures and results for each test.

\subsection{Density}

Densities were measured for all $\mathrm{UF}_{4}$ DUPoly samples. Density was calculated as sample mass divided by geometric volume. The data shown in Table 2 represent the mean and $2 \mathrm{~s}$ values for each sample type and DU loading. Except where noted, 10 each of the $2 \times 4$ and $1 \times 1$ samples were measured for a given DU loading. Disk samples were typically prepared in at least two different sample thicknesses for each DU loading, except for the $80 \mathrm{wt} \%$ loading, where all disk samples were of the same thickness. Five disk samples were prepared at the 50, 60 and $70 \mathrm{wt} \% \mathrm{UF}_{4}$ loadings; only 2 each were made at the 80 and $90 \mathrm{wt} \%$ loadings.

Table 2. UF $_{4}$ DUPoly Sample Densities $\left(\mathrm{g} / \mathrm{cm}^{3}\right)$.

\begin{tabular}{|c|c|c|c|}
\hline $\begin{array}{c}\mathbf{U F}_{\mathbf{4}} \text { Loading } \\
(\mathbf{w t} \%)\end{array}$ & $\begin{array}{c}\mathbf{2 \times 4} \\
\text { Samples }\end{array}$ & $\begin{array}{c}\mathbf{1 x 1} \\
\text { Samples }\end{array}$ & $\begin{array}{c}\text { Disk } \\
\text { Samples }\end{array}$ \\
\hline 50 & $1.56 \pm 0.03^{\mathrm{a}}$ & $1.57 \pm 0.03$ & $1.47 \pm 0.03$ \\
\hline 60 & $1.72 \pm 0.02^{\mathrm{b}}$ & $1.70 \pm 0.05$ & $1.64 \pm 0.05$ \\
\hline 70 & $2.17 \pm 0.02^{\mathrm{c}}$ & $2.24 \pm 0.05^{\mathrm{d}}$ & $2.05 \pm 0.06$ \\
\hline 80 & $2.73 \pm 0.03^{\mathrm{b}}$ & $2.80 \pm 0.08$ & $2.50 \pm 0.12$ \\
\hline 90 & $3.97 \pm 0.08^{\mathrm{e}}$ & $3.97 \pm 0.09^{\mathrm{e}}$ & $3.57 \pm 1.60$ \\
\hline
\end{tabular}

a 15 samples measured

b 9 samples measured

c 12 samples measured

d 14 samples measured

e 6 samples measured 


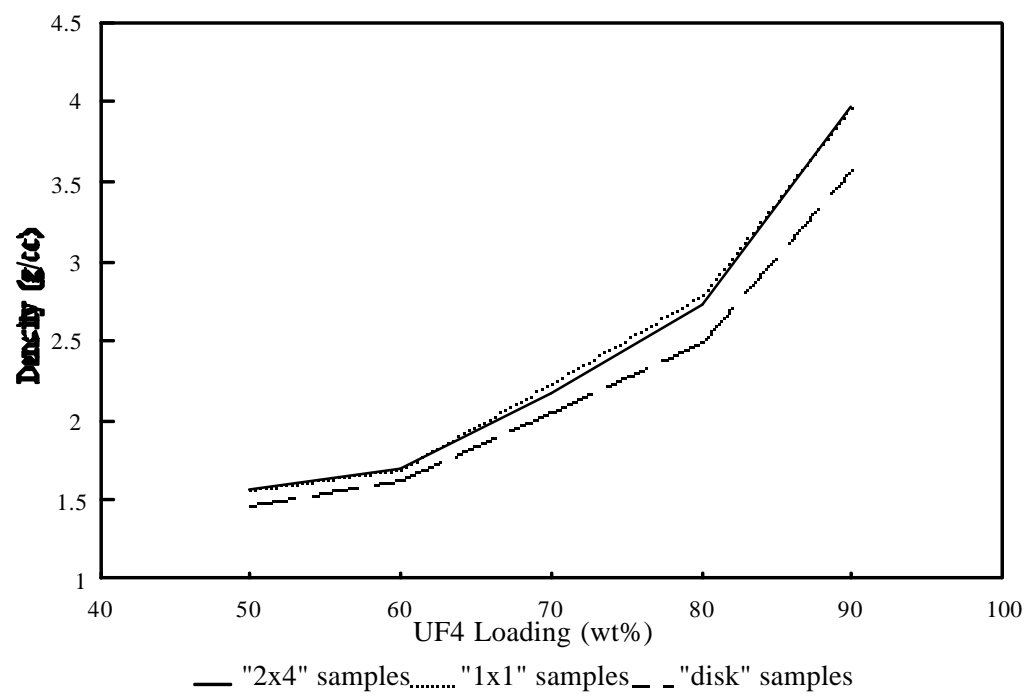

Figure 5. Density of DUPoly Samples as a Function of $\mathrm{UF}_{4}$ Loading.

As seen in Figure 5, sample densities increased significantly at high $\mathrm{UF}_{4}$ loadings due to the large disparity in density between the pure polyethylene and DU phases. Densities of " $2 \times 4$ " and "1x1" samples were nearly identical for all samples and were higher than comparable disk samples which were molded with a slightly lower compressive force. Despite the fact that the crystal density of $\mathrm{UF}_{4}$ is somewhat lower than $\mathrm{UO}_{3}\left(6.7 \pm .1\right.$ versus $\left.7.29 \mathrm{~g} / \mathrm{cm}^{3}\right),[10]$ density of DUPoly forms was nearly identical for the two DU aggregates. Because the particle size of the $\mathrm{UF}_{4}$ was smaller than the $\mathrm{UO}_{3}$ powder tested previously, the similar DUPoly densities for given DU loadings indicate a correlation with packing ability of the DU powder.

\subsection{Compressive Strength}

Compressive strength testing is a means of quantifying the mechanical integrity of a material. Force is exerted uniaxially on an unconstrained cylindrical sample until the sample fails. For this application, the maximum strength of the material as well as the mechanism by which it fails (plastic deformation vs brittle fracture) are of interest. Further, compressive strength can be useful to assess waste form performance following environmental testing. The Nuclear Regulatory Commission has recommended that licensable solidification processes must demonstrate a minimum waste form compressive strength of $0.41 \mathrm{MPa}(60 \mathrm{psi})$. Hydraulic cement waste forms must exceed $3.45 \mathrm{MPa}(500$ psi) to be considered for licensing.[11]

Compression testing was done in accordance with ASTM D-695, "Standard Test Method for Compressive Properties of Rigid Plastics." Five replicate 2x4 samples at the 50, 60, 70 and $80 \mathrm{wt} \% \mathrm{UF}_{4}$ loadings were tested. Only 3 samples with $90 \mathrm{wt} \% \mathrm{UF}_{4}$ were available for testing. Compressive testing was done using an Instron 5582 compression tester at a constant crosshead speed of $1.3 \pm 0.3 \mathrm{~mm}(0.05$ $\pm 0.01 \mathrm{in}.) / \mathrm{min}$. Compressive stress and strain were plotted past the yield point for each sample. From 
this data, maximum stress, strain, and deformation were computed at the maximum load point. Mean compressive yield strengths and \% deformation at yield are given in Table 3 for each $\mathrm{UF}_{4}$ waste loading.

Table 3. UF $_{4}$ DUPoly Compression Test Results.

\begin{tabular}{|c|c|c|c|}
\hline $\begin{array}{c}\text { UF } \\
\mathbf{4} \\
(\mathbf{w t} \text { Loading })\end{array}$ & $\begin{array}{c}\text { Yield Strength* } \\
(\mathbf{p s i})\end{array}$ & $\begin{array}{c}\text { Yield Strength* } \\
(\mathbf{M P a})\end{array}$ & $\begin{array}{c}\text { \% Deformation at } \\
\text { Yield* }\end{array}$ \\
\hline 50 & $3145 \pm 57$ & $21.7 \pm 0.4$ & $40.3 \pm 1.1$ \\
\hline 60 & $2228 \pm 270$ & $15.4 \pm 1.9$ & $26.3 \pm 5.5$ \\
\hline 70 & $1850 \pm 160$ & $12.8 \pm 1.1$ & $23.2 \pm 4.9$ \\
\hline 80 & $1682 \pm 116$ & $11.6 \pm 0.8$ & $9.3 \pm 2.3$ \\
\hline 90 & $2195 \pm 71$ & $15.1 \pm 0.5$ & $4.1 \pm 0.7$ \\
\hline
\end{tabular}

$*$ Mean $\pm 2 \mathrm{~s}$

$\mathrm{UF}_{4}$ DUPoly compressive strengths decreased with increasing $\mathrm{UF}_{4}$ as depicted in Figure 6 . At relatively low aggregate loadings, the plastic phase dominates the physical character of the composite, imparting a relatively tough and ductile nature. At $50 \mathrm{wt} \% \mathrm{UF}_{4}$, samples typically deform $>40 \%$ of their original height before failing. As the amount of powder in the sample increases, less plastic is available to bind the product resulting in a decreasing sample strength. At $90 \mathrm{wt} \% \mathrm{UF}_{4}$, the behavior apparently changes in that the powder is packed densely enough to dominate the physical behavior of the composite. Samples containing $90 \mathrm{wt} \% \mathrm{UF}_{4}$ exhibited only $4 \%$ deformation before failing. Similar results were observed during $\mathrm{UO}_{3}$ DUPoly testing, however, in that case, relatively large error bars made the trend more ambiguous. 


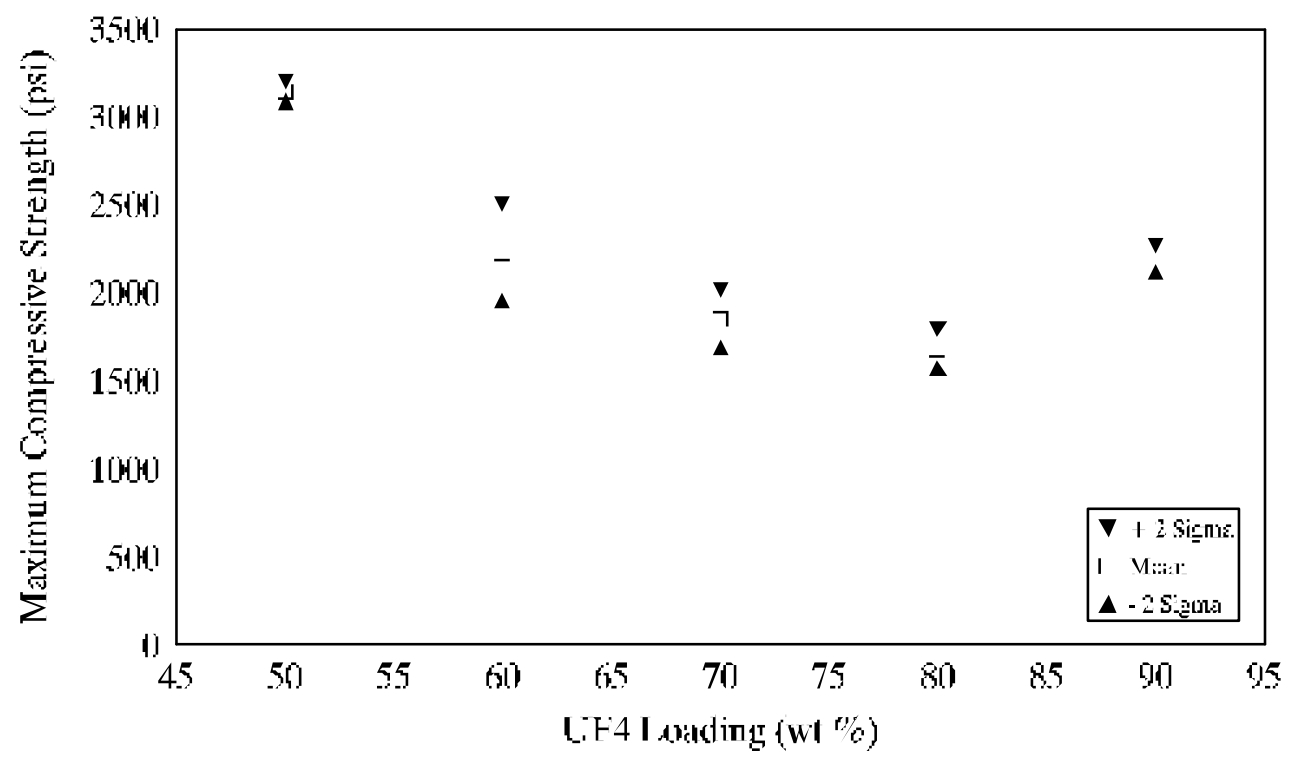

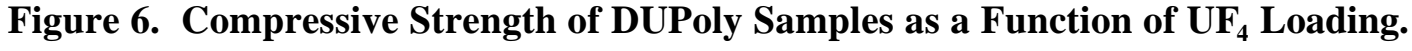

\subsection{Durability}

Scoping tests were conducted as a preliminary assessment of DUPoly potential for commercial development. Durability in aqueous and radiation environments was tested to determine possible deleterious effects on the product. Qualification under these environments would be required prior to consideration as an engineering material or shielding component.

\subsubsection{Water Immersion}

A 90 day immersion test was conducted on $2 \times 4$ samples at each of the five $\mathrm{UF}_{4}$ loadings. Samples were fully immersed in distilled water to determine possible deleterious effects of a water saturated environment. Three samples of $90 \mathrm{wt} \%$ DUPoly were grouped in a single polyethylene container. Four samples of each of the other $\mathrm{UF}_{4}$ loadings were similarly grouped together (i.e., four samples at $80 \mathrm{wt} \%$, four samples at $70 \mathrm{wt} \%$, etc.). Three liters of distilled water was added to each container. The test, done at ambient temperature, was a 90 day static immersion after which time the sample weights and volumes were re-measured. Sample compressive strengths were also tested following immersion, in the same manner as untested control samples reported earlier.

Mean sample compressive strengths of immersion tested samples were $2317 \pm 455,2265 \pm 482$, $2012 \pm 139,1748 \pm 101$, and $1848 \pm 576 \mathrm{psi}(15.98 \pm 3.13,15.61 \pm 3.32,13.88 \pm 0.96,12.06 \pm 0.70$, and $12.74 \pm 3.97 \mathrm{MPa}$ ), for 50, 60, 70, 80 and $90 \mathrm{wt} \% \mathrm{UF}_{4}$ DUPoly samples, respectively. Corresponding deformation at yield values were $22.9 \pm 6.9,25.2 \pm 9.6,24.5 \pm 3.2,11.4 \pm 1.9$, and 5.3 $\pm 3.2 \%$. Finally, post-test leach solutions were analyzed by inductively coupled plasma (ICP) spectroscopy to determine uranium concentration, and thus the uranium leach rate for each. These data are summarized in Table 4, below. 
Table 4. $\mathrm{UF}_{4}$ DUPoly Immersion Test Results.

\begin{tabular}{|c|c|c|c|c|c|}
\hline $\begin{array}{c}\mathbf{U F}_{\mathbf{4}} \\
\text { Loading }\end{array}$ & $\begin{array}{c}\text { Change in } \\
\text { Sample Mass }\end{array}$ & $\begin{array}{c}\text { Change in } \\
\text { Sample Volume }\end{array}$ & $\begin{array}{c}\text { Change in } \\
\text { Compressive } \\
\text { Yield Strength } \\
(\mathbf{\%})\end{array}$ & $\begin{array}{c}\text { Change in \% } \\
\text { Deformation at } \\
\text { Yield } \\
(\%)\end{array}$ & $\begin{array}{c}\text { Uranium } \\
\text { Leach Rate* }\end{array}$ \\
\hline 50 & $(\%)$ & +0.03 & -26.3 & -43.2 & $2.74 \times 10^{-6}$ \\
\hline 60 & +0.01 & +0.18 & +1.6 & -4.2 & $8.66 \times 10^{-6}$ \\
\hline 70 & +0.01 & +0.38 & +8.8 & +5.6 & $1.06 \times 10^{-5}$ \\
\hline 80 & +0.11 & +0.09 & +3.9 & +22.6 & $1.95 \times 10^{-5}$ \\
\hline 90 & -0.26 & +0.67 & -15.8 & +29.3 & $7.98 \times 10^{-5}$ \\
\hline
\end{tabular}

* Total mass of uranium leached divided by total mass of uranium in samples immersed divided by 90 days.

All final leach solutions were tinted green in color, the intensity varying with $\mathrm{UF}_{4}$ loading in the samples. While all samples withstood the 90 day immersion test with no visible change in appearance, data in Table 4 does shows some very subtle differences between leached and as-prepared (control) samples. These differences were primarily evident for $90 \mathrm{wt} \% \mathrm{UF}_{4}$ samples, where a loss in sample mass combined with an increase in sample volume corresponds with a leach rate which is about 30 times greater than for $50 \mathrm{wt} \% \mathrm{UF}_{4}$ samples. (That uranium leachate concentrations are greater than the $\mathrm{UF}_{4}$ solubility figure reported earlier indicates a possible hydrolysis reaction of the tetrafluoride to a more soluble form.) Compressive yield strengths of post-immersion samples did not correlate with $\mathrm{UF}_{4}$ loading, but data on percent deformation at yield did, with samples with lower $\mathrm{UF}_{4}$ content becoming less plastic as a result of water immersion (i.e., failing with less deformation) and samples with higher $\mathrm{UF}_{4}$ loadings becoming more plastic (i.e., greater elongation before failing).

\subsubsection{Gamma Irradiation}

Gamma irradiation stability tests were conducted using $\mathrm{UO}_{3}$ DUPoly as opposed to $\mathrm{UF}_{4}$ DUPoly. Gamma irradiation of archived $\mathrm{UO}_{3}$ DUPoly samples was conducted using BNL's Gamma Irradiation Facility (GIF). Samples containing 60, 70, 80, 85, and $90 \mathrm{wt} \% \mathrm{UO}_{3}$ were irradiated in air at a dose rate of approximately $1 \times 10^{6} \mathrm{rad} / \mathrm{hr}$ to a total dose of $1 \times 10^{9} \mathrm{rad}$. Cylindrical samples measuring 1 inch diameter by 1 inch tall (ALT samples) were tested. Unirradiated samples were compression tested and found to correlate well with $2 \times 4$ samples tested previously. The smaller samples were chosen for irradiation due to space constraints in the GIF. Changes in sample mass and volume and increases in mechanical strength of irradiated samples are summarized in Table 5. 
Table 5. $\mathrm{UO}_{3}$ DUPoly Gamma Irradiation Test Results.

\begin{tabular}{|c|c|c|c|c|}
\hline $\begin{array}{c}\text { UO }_{3} \\
\text { Loading }\end{array}$ & $\begin{array}{c}\text { Change in } \\
\text { Sample Mass }\end{array}$ & $\begin{array}{c}\text { Change in } \\
\text { Sample Volume } \\
(\mathbf{w t} \%)\end{array}$ & $\begin{array}{c}\text { Change in } \\
\text { Compressive } \\
\text { Yield Strength } \\
(\%)\end{array}$ & $\begin{array}{c}\text { Change in \% } \\
\text { Deformation at } \\
\text { Yield } \\
(\%)\end{array}$ \\
\hline 60 & +0.02 & -1.77 & +56.3 & -56.3 \\
\hline 70 & -0.03 & -0.77 & NA* $^{*}$ & NA* \\
\hline 80 & +0.01 & +2.15 & +136.0 & -41.1 \\
\hline 85 & +0.05 & +2.16 & NA* & NA* \\
\hline 90 & +0.07 & -0.39 & +199.6 & -36.3 \\
\hline
\end{tabular}

* NA = Data Not Available

The only visible effect of the $1 \times 10^{9}$ rad gamma dose was a slight darkening of the samples. As seen in Table 5, there were no statistically significant changes in sample mass or volume during testing. There were, however, significant changes in mechanical properties. Compressive strength increased for all samples, ranging from a $56 \%$ increase for $60 \mathrm{wt} \% \mathrm{UO}_{3}$ samples up to a $200 \%$ increase for $90 \mathrm{wt} \% \mathrm{UO}_{3}$ samples. Although only three data points were available, this trend appears to be linear in nature. Conversely, percent deformation at yield decreased after irradiation, with $60 \mathrm{wt} \% \mathrm{UO}_{3}$ samples approximately 56\% lower, and $90 \mathrm{wt} \% \mathrm{UO}_{3}$ samples approximately $36 \%$ lower than unirradiated samples. Again, these results appear to be linear.

These results were expected largely due to the well studied physics of polyethylene embrittlement with absorbed radiation dose. Up to a dose of about 1 x $10^{9}$ Rad, gamma energy causes cross-linking of long-chain polymer molecules, resulting in decreased plasticity of the material. At high DU loadings where there is the smallest amount of polyethylene binder, this embrittlement allows the $\mathrm{UO}_{3}$ phase to make a greater contribution to material strength compared to samples containing more polyethylene. Conversely, deformation at yield is controlled by the polyethylene phase. Thus, samples with larger amounts of polyethylene would be expected to show the largest radiation effect when comparing percent deformation at failure.

\subsection{Radiation Attenuation}

Following an internship at BNL, graduate student Scott Rutenkroger conducted experiments at the University of Missouri-Rolla to quantify attenuation of neutrons and gammas through the DUPoly matrix. Due to the long lead time required for sample shipment and setup, $\mathrm{UO}_{3}$ DUPoly disks, archived following FY-96 work, were used in this task. Disk samples containing 60, 70, 80 and $90 \mathrm{wt} \%$ "batch process" $\mathrm{UO}_{3}$, and 70, 80 and $90 \mathrm{wt} \%$ "continuous process" $\mathrm{UO}_{3}$ were shipped for testing. Disks of two different thicknesses were sent for each waste material and waste loading, making a total of 14 samples shipped. Radiation attenuations were measured using the two samples individually, and also stacked to create a third thickness. The material thickness measured ranged from about $0.5 \mathrm{~cm}$ to about $2 \mathrm{~cm}$ for each. 
For the gamma attenuation study, a cesium-137 $\left(\mathrm{Cs}^{137}\right)$ source was used to generate gamma rays at an energy of $661.64 \mathrm{keV}$. The Cs source was kept inside a shielded container with a plug opening on one end about one inch in diameter. The beam was further collimated by a lead brick with a 0.5 inch diameter hole placed 1.5 inches from the source opening. A 2.5 inch diameter sodium iodide (NaI) detector was aligned 29 inches from the source opening. A slot, in which the DUPoly disks could be inserted, was prepared in front of the detector. To divide out geometry factors, incomplete collimation of the source, and detector efficiency, counts were made both with and without shielding. All count times were for 300 live seconds to correct for detector dead time.

Neutron attenuation was performed using a plutonium-beryllium $(\mathrm{PuBe})$ source housed within a large water-shielded tub. A 4 inch diameter beam port, aligned with the source, extended from this assembly. Distance from the source to the beam port exit was 32 inches. DUPoly disks were placed up against the exit of the beam port such that the port was completely covered by the samples. An unshielded boron tetrafluoride $\left(\mathrm{BF}_{3}\right)$ detector, used to count thermal neutrons only, was located 4 inches from the beam port exit. Fast neutrons were counted using a cadmium and polyethylene shield around the detector. All source and shielding counts were performed for five minutes each, with the exception of the fast neutron counts.

Plots of gamma counts as a function of DUPoly thickness are shown in Figures 7 and 8 for batch and continuous process $\mathrm{UO}_{3}$. Although there was increasing attenuation for increasing weight percent $\mathrm{UO}_{3}$, an exponential fit of the data was expected but not observed. No discernable trend was observed in attenuation coefficients due to the large error in the data. For both material types, however, the mass attenuation coefficients calculated $\left(0.325 \mathrm{~cm}^{2} / \mathrm{g}\right.$ for batch $\mathrm{UO}_{3}$ samples, $0.450 \mathrm{~cm}^{2} / \mathrm{g}$ for continuous process $\mathrm{UO}_{3}$ ) were much greater than the coefficient for lead, which is around $0.11 \mathrm{~cm}^{2} / \mathrm{g}$. A lead control sample was not tested to verify this conclusion.

Similar plots of neutron counts for the two materials are shown in Figures 9 and 10. With the sole exception of the $70 \mathrm{wt} \%$ continuous DUPoly samples, the neutron attenuation follows an exponential fit very well. As a result, neutron removal coefficients can be calculated and shown to correlate with wt\% of DU. Unlike gamma attenuation, both hydrogenous and nonhydrogenous materials interact to attenuate neutrons. Thus comparisons of neutron removal coefficients are only valid for different materials (i.e., different DU loadings) of the same thickness. 


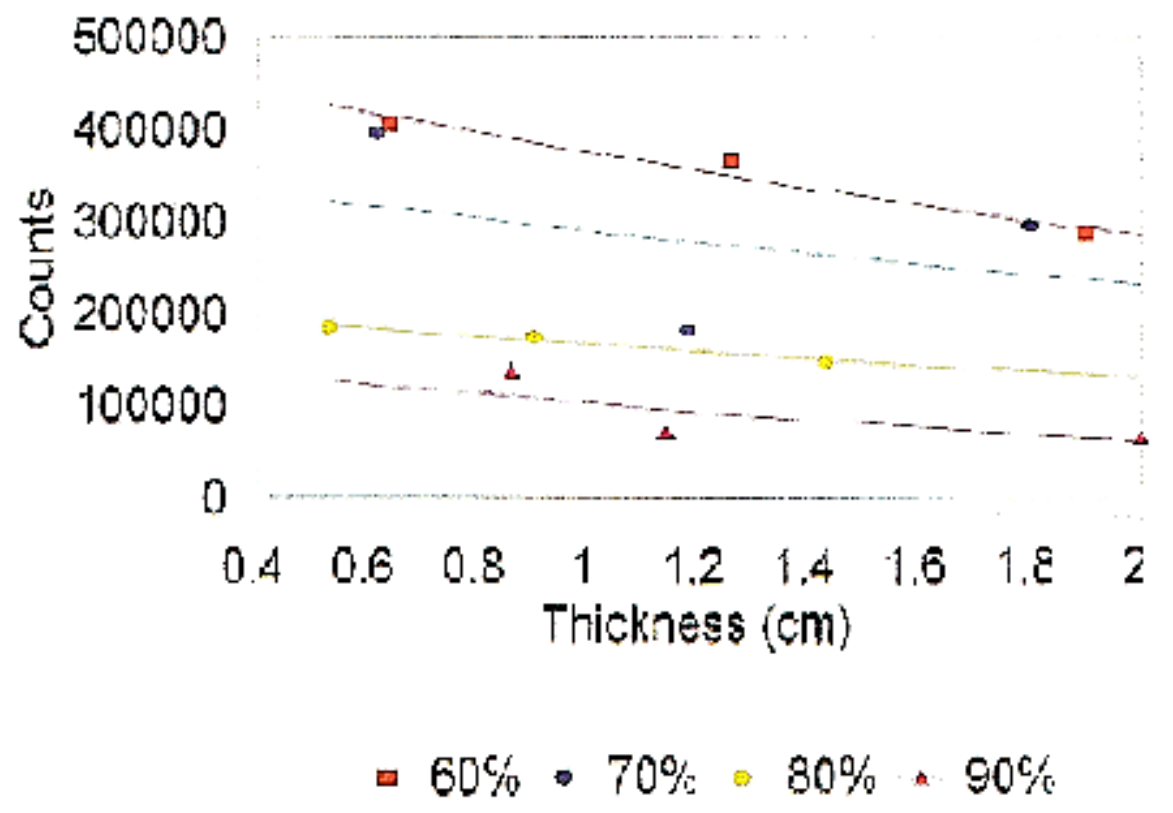

Figure 7. Gamma Attenuation of "Batch Process" UO $\mathrm{O}_{3}$ DUPoly Samples.

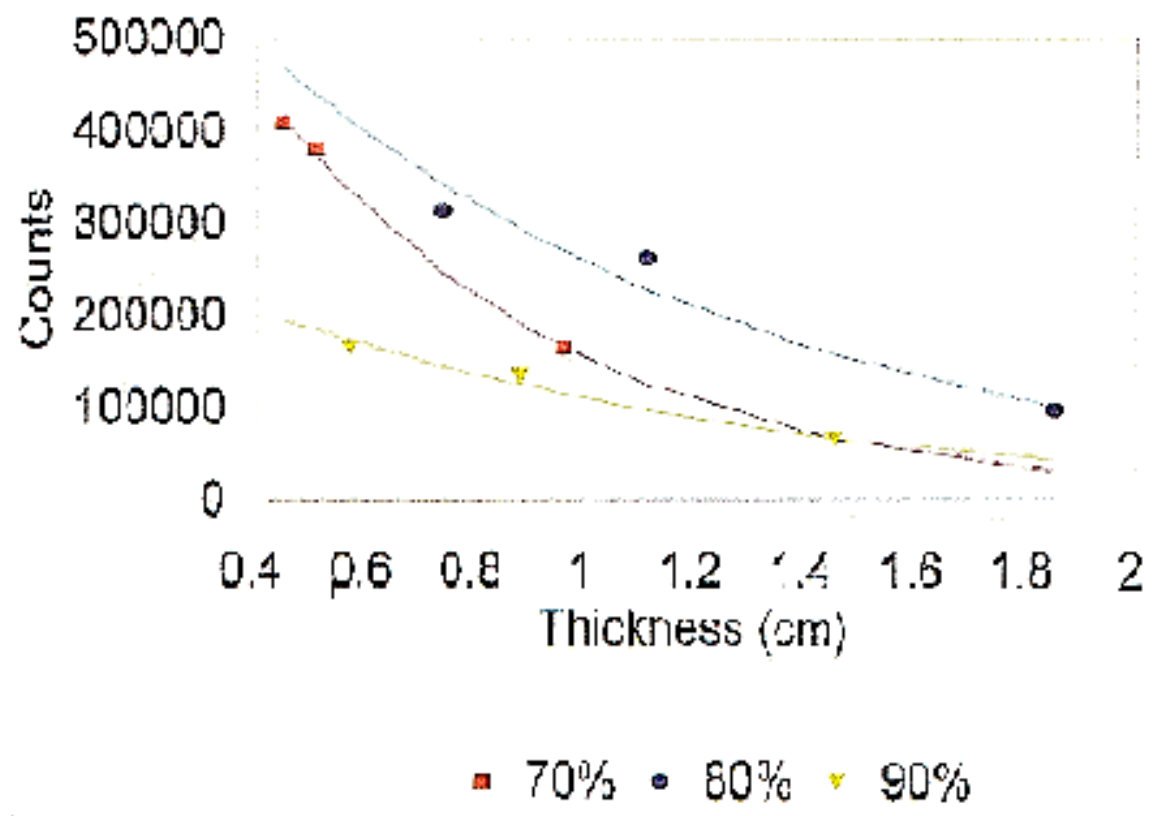

Figure 8. Gamma Attenuation of "Continuous Process" UO ${ }_{3}$ DUPoly Samples. 


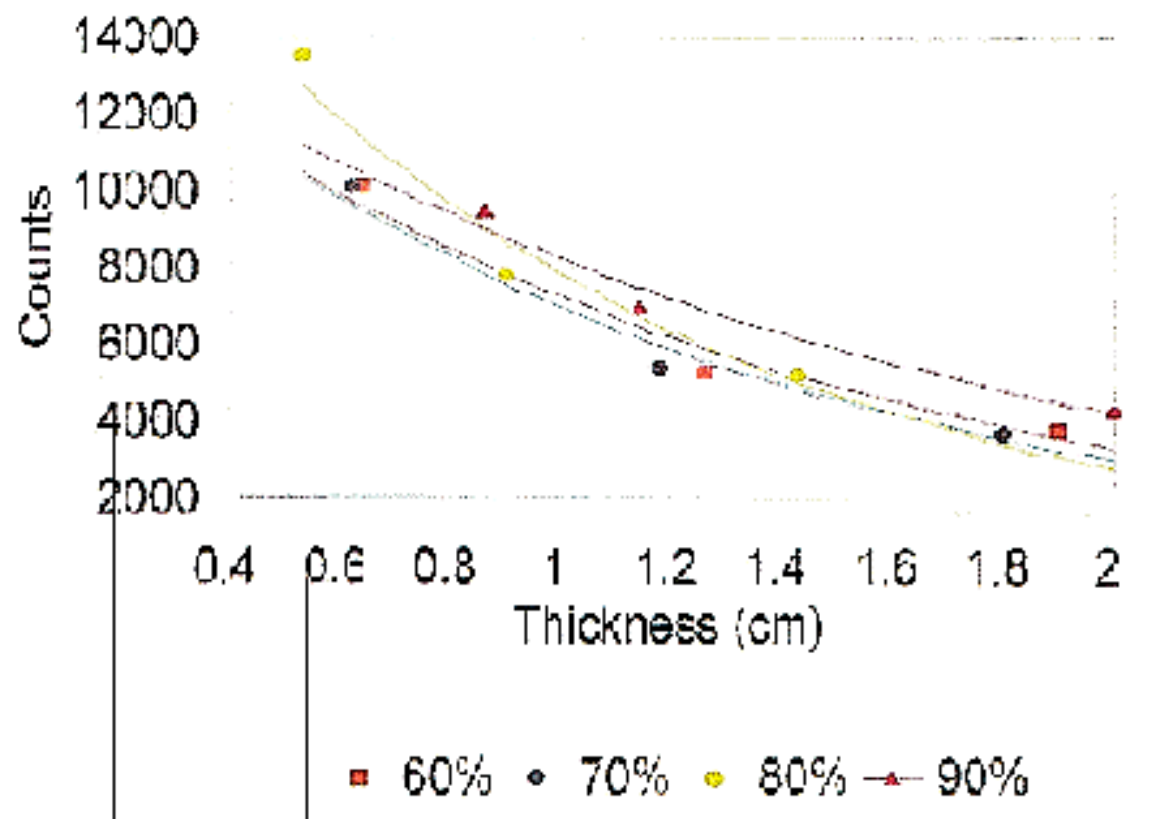

Figure 9. Neutron Attenuation of "Batch Process" UO $\mathrm{O}_{3}$ DUPoly Samples.

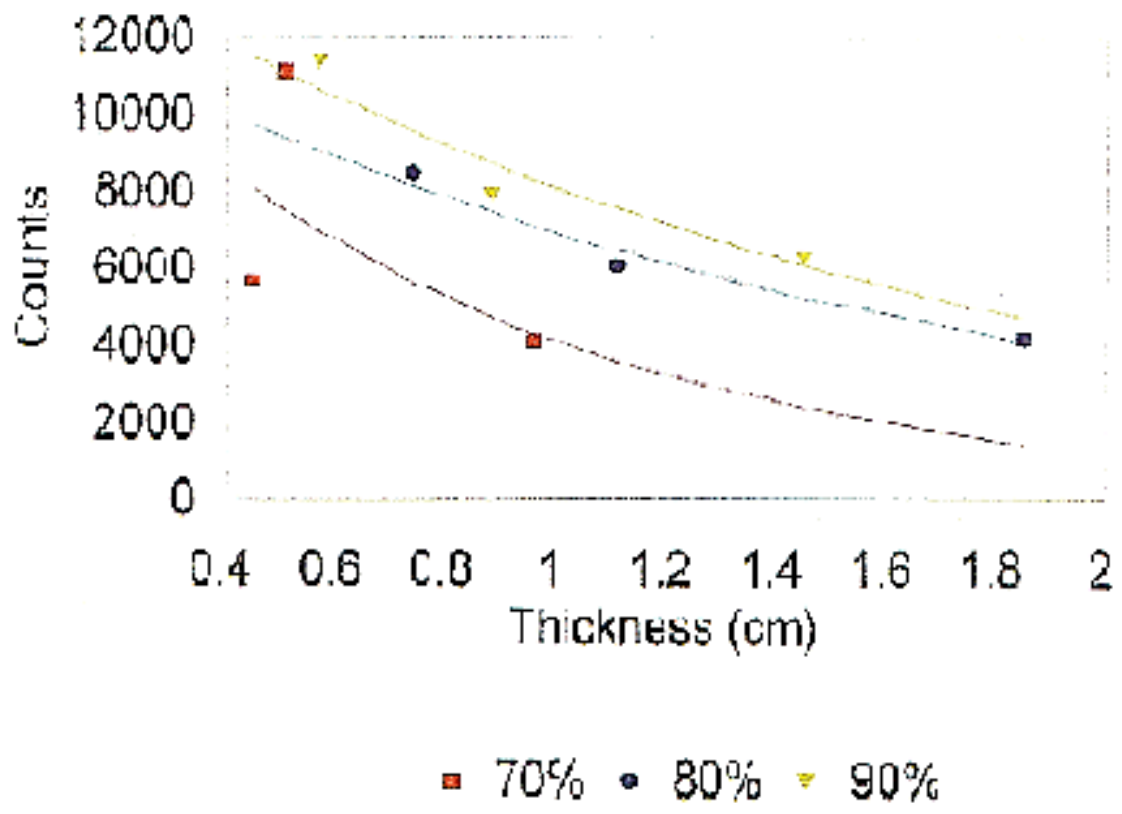

Figure 10. Neutron Attenuation of "Continuous Process" UO ${ }_{3}$ DUPoly Samples.

4. CONCLUSIONS 
The goals of this task were to characterize and optimize processibility of $\mathrm{UF}_{4}$ DUPoly using a single screw plastics extruder and perform testing to determine physical properties and durability of the product. These tests included density measurement, compression testing and water immersion testing. Another goal of this task was to characterize DUPoly in a gamma radiation environment. Gamma and neutron attenuation and physical changes due to an absorbed dose of $1 \times 10^{9} \mathrm{rad}$ gamma were examined. These tests were done using $\mathrm{UO}_{3}$ DUPoly material which had been successfully processed at $\mathrm{UO}_{3}$ loadings of up to $90 \mathrm{wt} \%$ in a prior effort. The $\mathrm{UO}_{3}$ DUPoly data serves as a baseline for which to compare $\mathrm{UF}_{4}$ DUPoly performance, as well as for determination of radiation effects.

$\mathrm{UF}_{4}$ DUPoly samples were successfully prepared atDU loadings of 50, 60, 70, 80 and $90 \mathrm{wt} \%$ $\mathrm{UF}_{4}$. Successful preparation was judged to be formation of homogeneous, dense monoliths with reproducible physical characteristics and performance. Unlike $\mathrm{UO}_{3}$ processing, however, where screw squealing (due to friction of the DU between the extruder screw and barrel) was the only event of any note, some difficulties were observed during $\mathrm{UF}_{4}$ processing. These included periodic evolution of gas (probably due to entrained air associated with very fine particles) and occasional irregularity in extruder output, expecially at higher DU loadings. At the $90 \% \mathrm{UF}_{4}$ loading, processing was deemed unsuccessful in that extrudate output was discontinuous, with output flow ceasing for periods of 15-45 seconds, then continuing for periods of 30-60 seconds. A vented extrusion or kinetic mixing process would be expected to relieve any gas generated, thereby avoiding the problems seen here.

$\mathrm{UF}_{4}$ DUPoly densities were measured for three different sample types at each DU loading. Highest values were recorded for 1 inch diameter by 1 inch tall cylindrical samples which were formed under the highest pressure (approximately $250 \mathrm{psi}$ ). Mean values were $1.57 \pm 0.03,1.70 \pm 0.05,2.24$ $\pm 0.05,2.80 \pm 0.08$, and $3.97 \pm 0.09 \mathrm{~g} / \mathrm{cm}^{3}$, for samples at 50, 60, 70, 80 and $90 \mathrm{wt} \% \mathrm{UF}_{4}$, respectively. Despite the fact that theoretical crystal density of $\mathrm{UF}_{4}$ is somewhat lower than $\mathrm{UO}_{3}$, density of DUPoly forms was nearly identical for the two DU aggregates. Because the particle size of the $\mathrm{UF}_{4} \mathrm{was}$ smaller than the $\mathrm{UO}_{3}$ powder tested previously, the similar DUPoly densities for given DU loadings indicate a correlation with packing ability of the DU powder.

$\mathrm{UF}_{4}$ DUPoly compressive strengths displayed a decreasing trend from a high mean value of $3145 \pm 57 \mathrm{psi}(21.7 \pm 0.4 \mathrm{MPa})$ for $50 \mathrm{wt} \% \mathrm{UF}_{4}$ to a low of $1682 \pm 116 \mathrm{psi}(11.6 \pm 0.8 \mathrm{MPa})$ for 80 $\mathrm{wt} \% \mathrm{UF}_{4}$. Compressive strength increased slightly at $90 \mathrm{wt} \% \mathrm{UF}_{4}$, to $2195 \pm 71 \mathrm{psi}(15.1 \pm 0.5 \mathrm{MPa})$. This magnitude and trend was similar to data observedfor as-prepared $\mathrm{UO}_{3}$ DUPoly. Meanwhile, 50 $\mathrm{wt} \% \mathrm{UF}_{4}$ samples deformed $40.3 \pm 1.1 \%$ of their original height before failing, compared with a deformation at yield of only $4.1 \pm 0.7 \%$ for $90 \mathrm{wt} \% \mathrm{UF}_{4}$ DUPoly. This data is also in line with $\mathrm{UO}_{3}$ DUPoly results and is largely a physical process, dependent on the amount of powder (DU), and thus the amount of plastic in the sample.

Water immersion testing for 90 days produced no visible degradation of any $\mathrm{UF}_{4}$ DUPoly samples. Subtle differences were noted, however, following compression testing of immersion tested specimens. Compressive yield strengths of post-immersion samples did not correlate with $\mathrm{UF}_{4}$ loading, but data on percent deformation at yield did, with samples with lower $\mathrm{UF}_{4}$ content becoming less plastic as a result of water immersion (i.e., failing with less deformation) and samples with higher $\mathrm{UF}_{4}$ loadings becoming more plastic (i.e., greater elongation before failing). 
$\mathrm{UO}_{3}$ DUPoly samples gamma irradiated to $1 \times 10^{9}$ rad exhibited a significant increase in compressive strength for all samples, ranging from a 56\% increase for $60 \mathrm{wt} \% \mathrm{UO}_{3}$ samples up to a $200 \%$ increase for $90 \mathrm{wt} \% \mathrm{UO}_{3}$ samples.

Gamma shielding studies of $\mathrm{UO}_{3}$ DUPoly showed increasing attenuation for increasing weight percent $\mathrm{UO}_{3}$. No discernable trend was observed in attenuation coefficients due to the large error in the data. For both "batch process" and "continuous process" $\mathrm{UO}_{3}$ samples tested, however, the mass attenuation coefficients calculated were much greater than the coefficient for lead, which is around 0.11 $\mathrm{cm}^{2} / \mathrm{g}$. Neutron attenuation genserally followed an exponential fit very well. As a result, neutron removal coefficients were calculated and shown to correlate with wt\% of DU. Unlike gamma attenuation, both hydrogenous and nonhydrogenous materials interact to attenuate neutrons. Thus comparisons of neutron removal coefficients are only valid for different materials (i.e., different DU loadings) of the same thickness.

\section{REFERENCES}

1. $\quad$ Kalb, P.D. and P. Colombo, "Polyethylene Solidification of Low-Level Wastes, Topical Report," BNL-51867, Brookhaven National Laboratory, Upton, NY, October 1984.

2. Kalb, P.D., J.H. Heiser, III, and P. Colombo, " Polyethylene Encapsulation of Nitrate Salt Wastes: Waste Form Stability, Process Scale-up, and Economics," BNL- 52293, Brookhaven National Laboratory, Upton NY, July 1991.

3. Kalb, P.D., J.H. Heiser, and P. Colombo, "Long-Term Durability of Polyethylene for Encapsulation of Low-Level Radioactive, Hazardous, and Mixed Wastes," Emerging Technologies in Hazardous Waste Management III, D.W. Tedder and R.G. Pohland, ed., American Chemical Society Symposium Series 518, Washington, D.C., 1993.

4. Kalb, P.D., and P.R. Lageraaen, "Full-Scale Technology Demonstration of a Polyethylene Encapsulation Process for Radioactive, Hazardous, and Mixed Wastes," Journal of Environmental Science and Health, in press.

5. Kalb, P.D., P.R. Lageraaen, B.R. Patel, D.C. Sangster, and A. Poste, "Development of a PreTreatment System for Polyethylene Encapsulation of Mixed Wastes," Waste Management, Tucson, AZ, March 1997.

6. Kaplan, S.A., "Depleted Uranium Market Study," Kapline Enterprises, Inc., Y/NA 1801, August 1995.

7. Adams, J.W., P.R. Lageraaen, and P.D. Kalb, "Polyethylene Encapsulation of Depleted Uranium Trioxide," Emerging Technologies in Hazardous Waste Management VIII, September 1996.

8. The Chemistry of Uranium, Chapter 9, Uranium Halides, ed. E.H.P. Cordfunke, Elsevier Publishing Co., 1969. 
9. Katz, J.J., and E. Rabinowitch, The Chemistry of Uranium, McGraw-Hill, 1951.

10. CRC Handbook of Chemistry and Physics, ed. R.C. Weast and M.J. Astle, CRC Press, Inc, Boca Raton, FL, 1981.

11. U.S. Nuclear Regulatory Commission, "Technical Position on Waste Form", Revision 1, Final Waste Classification and Waste Form Technical Position Papers, US NRC, Washington, DC, January 1991. 